\title{
Improving Outcomes for Criminal Offenders with Serious Mental Illness
}

\section{Lorena Fulton}

Assistant Professor of Social Work, Ohio University Zanesville, 1425 Newark Rd., Zanesville, Ohio 43701, USA

\begin{abstract}
This qualitative study used an action research design and an appreciative inquiry methodology. The key purpose of this study was to innovate collaborative processes between the Mental Health Court and mental health service providers as they work together to design new strategies to reduce recidivism among adult offenders with serious mental illness. This study followed a pragmatic approach that allowed for evolving assumptions about the causes that influence the outcomes. The stakeholders in this study were legal professionals and mental health service providers. Individual interviews, focus groups, and a survey were used to explore effective ways to help offenders with serious mental illness to coexist successfully in the community and avoid further incarceration. The outcome of this research was an improvement in collaboration between stakeholders to ensure successful transition from jail to the community, for offenders with serious mental illness. This collaboration removed barriers to avoiding recidivism and re-incarceration among adults with serious mental illness and improved policy and procedure followed by the mental health service providers and court professionals.
\end{abstract}

\section{Publication History:}

Received: July 27, 2017

Accepted: October 02, 2017

Published: October 04, 2017

\section{Keywords:}

Appreciative Inquiry, Offenders with mental illness, chronically incarcerated, Recidivism, Reincarceration, Publically funded human services, psychosocial problems, Correctional institutions, Participating stakeholders, Service adherence

\section{Introduction}

The purpose of this appreciative inquiry project was to innovate collaborative processes between the Mental Health Court (MHC) and mental health service providers, particularly as they work together to design new strategies to reduce recidivism among adult offenders with serious mental illness. The study objective was to reduce recidivism among criminal offenders with serious mental illness. The study included legal professionals and mental health service providers. A survey, individual interviews, and focus groups were used to explore effective ways to help offenders with serious mental illness to coexist successfully in the community and avoid further incarceration. This study was prompted by observations from a community prisoner review team that found people with serious mental illness often struggle more than their counterparts to overcome legal involvement and chronic incarceration. The results from this study will be useful to improve outcomes for offenders with serious mental illness.

The revolving door, between jail and the community that some people with serious mental illness find themselves in, highlights challenges between the legal system and the outpatient mental health care system. The continuation of care between institutions of incarceration and the community is proven difficult due to differences in perspective between mental health professionals and legal professionals. This is a nation-wide problem and changes are needed at the state policy level in order to have a significant impact on improvement of the continuation of care [1]. Not only will such an impact improve the quality of life for these individuals, it will also save money because it is much more expensive to incarcerate individuals than to provide outpatient services, and the cost savings to taxpayers will be considerable [2].

Mental health intervention in a correctional institution helps the person to stabilize emotionally and increases the likelihood of initiating and following through with community-based services after release [1]. Treatment on the inside helps the prisoner to maintain hope and cope with the challenges of being incarcerated, and it leads to a more stable person upon release. Intervention in the institution includes collaboration with the community-based services, which increases the likelihood of continued care. Collaboration assists with enrollment in outpatient services without relying on the prisoner to take the initiative. The outpatient agency then has the opportunity to engage the person in active treatment within hours of release, which ultimately increases the likelihood of continued care. These mental health interventions and continued care have not always been available or sufficient within the correction system.

Outpatient service adherence and formal community supervision are positive factors in preventing recidivism, as found in a study completed by Gideon [3]. These two factors are related because they both involve ongoing contact and monitoring of lifestyle and behavior. Often, local jails hold offenders with mental illness only long enough for them to transfer to a mental health facility or for a short time until release. The jails can be an effective link to outpatient mental health services [3], if continued care is sufficient.

Continued care between jail and outpatient services is often in sufficient due to differences in medication formulary, and a drastic change in the level of supervision [4]. In the end, it is much more expensive to incarcerate individuals than to provide outpatient services, especially when considering the costs of arrest and court expenses. Findings from this study helped a county in the southwest see improvement in the following ways: The study helped to improve interagency communication between the courts and mental health service providers, related to specific case details and to exchange ideas related to effective engagement that are duplicable between agencies.

While most people with serious mental illness do not break the law, those who do and are incarcerated, often struggle more than their counterparts to overcome legal involvement and chronic "Corresponding Author: Dr. Lorena Fulton, Assistant Professor of Social Work, Ohio University Zanesville, 1425 Newark Rd., Zanesville, Ohio 43701, USA; E-mail: fultonl@ohio.edu

Citation: Fulton L (2017) Improving Outcomes for Criminal Offenders with Serious Mental Illness. Int J Psychol Behav Anal 2: 132. doi: https://doi. org/10.15344/2017/2455-3867/132

Copyright: (c) 2017 Fulton. This is an open-access article distributed under the terms of the Creative Commons Attribution License, which permits unrestricted use, distribution, and reproduction in any medium, provided the original author and source are credited. 
incarceration [5]. However, jail administrators have a responsibility to see that inmates with serious mental illness are not denied medications and treatments that would aid in their rehabilitation. Researchers demonstrated that the denial of treatment for inmates with serious mental illness is a nation-wide problem [1]. In the end, it is much more expensive to incarcerate individuals than to provide outpatient services, especially when considering the costs of arrest and court costs [1].

Outpatient service adherence and formal community supervision are positive factors in reducing recidivism [3]. Outpatient treatment of serious mental illness includes regular visits with the prescribing psychiatrist. It has been documented that with proper medication, the disease progresses much more slowly, and people are often able to function well in the community [6]. Other research shows that when a doctor, outpatient services, or the court system does not properly supervise offenders with mental illness, the outpatient plan becomes futile [4]. Therefore, the proper engagement of MHC stakeholders is necessary for effective results. In this research, the role, perception, barriers, and responsibilities of the stakeholder group were analyzed to address the problem of insufficient continued care between the jail and outpatient mental health services.

\section{Literature Review}

Baillargeon, Hoge, and Penn [7] added a "history of incarcerations" to a study in Texas and found that current inmates who carried a diagnosis of major depressive disorder, bipolar disorder, serious mental illness, or other psychosis were much more likely to have multiple incarcerations in their history than prisoners without these diagnoses. The study concluded that inadequate mental health services during and after incarceration resulted in adverse clinical outcomes, disability, social isolation, and criminal recidivism [7]. The authors determined that people with serious mental illness and a history of prison incarceration are more resistant to mental health treatment and that re-entry into the community is complicated by these social and behavioral factors.

When considering recidivism outcomes for MHC defendants, Dirks-Linhorst, and Linhorst [8] found that the re-arrest rate of defendants who successfully completed the program was $14.5 \%$, compared to $38 \%$ among defendants negatively terminated from the program and $25.8 \%$ among defendants who chose not to participate. However, the study also highlighted substance abuse as a factor against avoiding re-arrest. The authors noted that substance abuse among persons with mental illness exacerbates psychiatric symptoms, treatment noncompliance, strained relationships, aggressive and violent behavior, and housing instability, all of which can influence the ability of defendants to avoid re-incarceration [8].

In the 2006 Special Report compiled by the Bureau of Justice, there is a demonstrated correlation between psychosocial problems that are of greater cost to the public and the lack of resources applied to psychiatric treatment in prison or jail [9]. For example, violence among prisoners requires more expensive supervision, re-incarceration is increased cost, and prisoners who are released homeless are an additional cost in human services and create a higher risk to the community. These ongoing problems may be mitigated with effective treatment during the incarceration and after release because the treatment will increase emotional stability and decrease psychiatric symptoms [10]. Makarios, Steiner, and Travis [11] found a positive correlation between completing a GED or high school

Int J Psychol Behav Anal

ISSN: 2455-3867 diploma (in jail or prison), and maintaining stable employment and housing (after release) and avoiding re-incarceration.

After release, people with mental illness are often homeless and found to be abusing substances [12]. Over half of the inmates with severe mental disorders had a co-occurring substance use disorder upon arrest, and $90 \%$ at some time in their lifetime [13]. Soderstrom [13] compiled statistics related to the prevalence of mental illness in prisons and found a $70 \%$ reduction in the recidivism rate for drug offenders who completed a prison based substance abuse and work release program (p. 13). Of equal importance in reducing recidivism to prison-based substance abuse treatment was continued treatment after release and community-based supervision [3]. More research related to specific jail diversion programs that link offenders to mental health, substance abuse, and criminal justice prevention programs is needed to demonstrate the effect of these programs. Although not a clinical study of mentally ill offenders, Walters [14] identified age and prior charges to be factors predictive of recidivism.

Psychosocial problems in the community increase the likelihood of initial arrest or recidivism. State prisoners who had a mental illness were twice as likely to have been homeless in the year before their arrest as prisoners without mental illness [9]. Among jail inmates, about $14 \%$ who had a mental illness had lived in a foster home or other institution growing up, compared with $6 \%$ of inmates without mental illness [9]. Additionally, inmates with mental retardation are over-represented in correctional systems [13].

Advantages of mental health intervention will outweigh the risks, damages, and other consequences. Research of MHCs in New York and Nevada showed that more than 90 percent of the participants of two sites correctly comprehended the expectations of regular meetings with the judge, and allowed the court to access documents related to the need for psychotropic drugs [2]. When asked to identify the advantages and disadvantages of participation at MHCs, participants identified disadvantages as a stigma associated with participation in the MHC, increased tight supervision, time required to participate in treatment, and requirements to abide by a court decision or face sanctions [2].

\section{Methodology}

The purpose of this studywas to reduce recidivism through improving outpatient mental health service delivery for criminal offenders with serious mental illness. The courts also have a responsibility to advocate for this vulnerable population. This appreciative inquiry led to better collaboration between the legal system and the mental health service system. Participating stakeholders included attorneys, city police supervisors, and mental health service providers. The desired outcome of this research was to increase engagement in outpatient services so that defendants will spend more time in the community and less time incarcerated.

The data collection and analysis process was designed to analyze information in the interest of creating a strategy for positive change with respect to improving collaboration between the legal and mental health service systems on behalf of offenders with serious mental illness. This process allowed the researcher to successfully collect survey data that reinforced the plan for individual interview starter questions and helped to improve on starter questions for the first focus group meeting (Appendix A). The individual interviews demonstrated the commitment of research participants and their 
insight into the needs and strengths of the current collaboration between the systems. The first focus group allowed for open-ended brainstorming of ideas with a focus on improving collaboration between the legal and mental health systems. The second focus group honed the emphasis toward improvements that this research group may have influence over improving. The third and final focus group meeting solidified a list of issues to address and resulted in action steps. The results of this study are intended to promote collaboration with the professionals in the legal system and the community mental health provider network.

$\mathrm{AI}$ is a strengths-focused approach that considers what works well with interventions or collaborations. In this case, AI was applied to innovate collaborative processes between the MHC and mental health service providers to identify and duplicate strategies that may reduce recidivism among adults with serious mental illness. Lawyers on both sides, mental health service providers, and professionals from the city police department and adult probation were utilized as stakeholders. Individual interviews, focus groups, and a survey were applied in an appreciative inquiry to explore effective ways to help offenders with serious mental illness to coexist successfully in the community and avoid further incarceration.

The goal of the study was to improve service coordination between the courts and providers of community-based services. The proposed research concept was based on the tendency for psychosocial problems in the community to increase the likelihood of initial arrest and recidivism among adults with mental illness. Mental health treatment for these special populations is a matter of ethics both inside and outside of correctional institutions. The desired outcome of this research was to improve collaboration between stakeholders to ensure successful transition from prison or jail to the community, for offenders with serious mental illness.

\section{Participants}

Study stakeholders were recruited from the MHC contact list, which was a publically available list of professional MHC stakeholders. The primary participant group of 8-10 stakeholders was a group of mental health service providers that engaged in outpatient services with defendants in the county MHC. This group participated in the focus group and in the quarterly community meeting.

Criteria for participant inclusion was participation in the Mental Health Court process and or seasoned (two or more years) community service providers that work with offenders with serious mental illness who are involved in the MHC. Exclusions were MHC stakeholders who are supervisees of the researcher, and clinical staff that look to the researcher for informal clinical feedback. Administrators who do not provide direct service were also excluded, as were judges, attorneys, and probation officers who are not represented by a MHC Defendant. If a supervisor and a supervisee both volunteer for the study, one was excluded. Finally, stakeholders who have an interest with offenders with serious mental illness who are not eligible for MHC services are excluded so that the data was pure and relates to the coordination of care that was provided by the MHC.

Study participants were part of an existing group of professionals in the MHC that meet weekly to discuss cases and system improvement ideas. The non-probability purposive sample allowed the researcher to focus on priority barriers that inhibit collaboration between the justice and mental health service systems [15]. It also selected professionals who are familiar with the MHC in this community. This was expanded to include other stakeholders, such as police officers and a prosecutor so that a more diverse perspective could be gleaned. This group participated in the survey and the three focus groups. Only mental health service providers participated in the individual interviews.

The demographics of the research group were diverse in terms of race, gender, and education level. Of the eight participants, four are of European ethnic origin, three identify with Latino culture, one was African American, and one added to the Latino group identifies as Native American. Six of the participants are women and two are men. Finally, the educational background was very diverse. One participant holds a Juris Doctorate, two hold Master's Degrees, two hold Bachelor's Degrees, and three have not attended college. Finally, one of the participants serves as an attorney, three provide therapeutic intervention, and four coordinate care for defendants in the MHC.

There was emphasis on natural environments such as public meeting spaces and smaller groups of six to eight participants [16]. Therefore, the qualitative data was collected at the participant's place of work for individual interviews and at the county courthouse for the focus groups. Academic researchers often use focus groups to gather qualitative data. By having three meetings for the focus group and three individual interviews with each participant, data saturation was achieved [17].

\section{Instruments}

A Likert-scaled survey titled "What are mental health service providers' perceptions of how the county Mental Health Court can increase engagement in outpatient services so that defendants will spend more time in the community and less time incarcerated" was developed (Appendix A). According to Stringer and Dwyer [18], interviews and focus groups are effective tools, as they were primary entry points into an action research process, and because they help to support the research group's focus on inclusion and problem solving strategies by those most affected by an issue. Broad and general data were gathered and associated with system strengths and needs in mental health service delivery for criminal offenders with serious mental illness. This data was only gathered for defining perceptions associated with removing barriers and duplicating methods that prove successful. It was gathered early in the data-gathering phase so that there would be a focus on other data collection points.

\section{Data Analysis}

The overarching question for this AI study was: "What are mental health service providers' perceptions of how the county MHC can increase engagement in outpatient services so that defendants will spend more time in the community and less time incarcerated?" This broader question has been divided into four sub questions. Table 1 identifies the four sub questions along with the data sources used to triangulate the information collected. The focus groups, interviews, and the survey were used to triangulate data to improve confidence in the study. This validation will improve research outcomes by investigating how service engagement can best result in avoiding re-incarceration. Triangulation means applying multiple research sources, methods, and perspectives to verify or emphasize the similar results [18]. 


\begin{tabular}{|l|l|l|}
\hline Research Sub Questions & Data Source 1 & Data Source 2 \\
\hline $\begin{array}{l}\text { What are the mental health service stakeholders' perceptions of how to increase } \\
\text { engagement in services? }\end{array}$ & Survey & Individual Interviews \\
\hline $\begin{array}{l}\text { What do the mental health service provider stakeholders identify as barriers to } \\
\text { addressing the current rate of recidivism? }\end{array}$ & $\begin{array}{l}\text { Individual } \\
\text { Interviews }\end{array}$ & Focused group \\
\hline $\begin{array}{l}\text { What are the mental health service stakeholder's concerns about service engagement } \\
\text { time and quality? }\end{array}$ & Survey & Individual Interviews \\
\hline $\begin{array}{l}\text { What are the mental health service provider stakeholder's perceptions of their roles } \\
\text { and responsibilities in the increasing the Defendants' level of commitment to service } \\
\text { engagement? }\end{array}$ & $\begin{array}{l}\text { Individual } \\
\text { Interviews }\end{array}$ & Survey \\
\hline
\end{tabular}

Table 1: Sources of Data Triangulation and Research Sub Questions.

\section{Survey}

The survey, which was intended to add validity to the starter questions and direction of the interviews and focus groups, was deployed through Survey Monkey, which provided a basic analysis of how many participants answered each question, along with a percentage of the respondents that chose each weight on the Likert scale. Of the 11 stakeholders who were invited to participate, eight (72\%) responded and all eight answered all six of the survey questions (Appendix A). The purpose of the survey was to find out more about the respondents' perceptions about system strengths and needs in mental health service delivery for adults with serious mental illness who are involved in the legal system. The following key words were primary: help, service, and improving. The word "help" was associated with services helping offenders with serious mental illness and with collaboration being helpful to stakeholders' job success and to offender outcomes. "Service" was associated with mental health treatment services in terms of engaging offenders with serious mental illness and with the effectiveness of those services to improve outcomes for offenders. "Improving" spoke to the collaborative efforts of the two systems and to the effectiveness of mental health interventions to improve outcomes.

The Likert Scale had five options for each item, which included "Strongly Agree", "Agree", "Neutral", "Disagree", and "Strongly Disagree". Item number one, "Engagement in outpatient mental health services helps people with serious mental illness to avoid legal problems", resulted in 25\% "Strongly Agree", 50\% "Agree", and 25\% "Disagree". Two respondents added a comment which stated, "Outpatient mental health services doesn't' help people with serious mental illness avoid legal problems, the person has a choice if they do something illegal", and "People with these issues continue to have legal problems to some extent."

Item number two stated, "Current practice associated with engaging offenders with serious mental illness in mental health services is adequate in this county." $37.5 \%$ chose "Agree", $25 \%$ chose "Neutral" and $37.5 \%$ chose "Disagree". Added comments stated, "Somewhat better than it was, needs constant adjustment and re-adjustment", and "Some offenders may get the help they need while others are in and out of the system and continue being contacted by law enforcement". Item number three stated, "Community stakeholders (service providers, the courts, probation, and law enforcement) agree on risk factors for recidivism that can be mitigated with mental health services." Here, $50 \%$ of the respondents chose "Agree", 37.5 chose "Neutral" and $12.5 \%$ chose "Disagree". There were no additional comments added to item number three.
The fourth item stated, "I fully understand my roles and responsibilities as a mental health service provider or other professional who helps offenders with serious mental illness." All respondents, or $100 \%$, chose "Agree" for this item and there were no additional comments added. Item number five stated, "There is a friendly feeling between service providers and other stakeholders." $37.5 \%$ chose "Agree", $50 \%$ chose "Neutral" and $12.5 \%$ chose "Disagree. One comment was added which stated, "It's improving all the time." The sixth and final item stated, "There is a lot of wasted time in meetings about specific cases with similar barriers to treatment." Here, $12.5 \%$ chose "Agree", 37.5\% chose "Neutral" and 50\% chose "Disagree". The only comment that was added to this item was, "It is definitely not a waste of time."

\section{Qualitative Analysis}

The qualitative data for this project was collected through individual interviews and focus groups. The researcher discussed the data collection procedures, which included the use of written notes and audio recordings, during the informed consent procedures. Participants were also informed that the recordings would be transcribed and themes would be analyzed. All participants agreed and signed the Informed Consent without question.

In terms of needing to modify the questions planned for the individual interviews and focus groups (Appendix A) based on the survey results, there was general agreement that engagement in outpatient services helps to improve the recidivism rate for offenders with mental illness. The first proposed focus group question was, "What are your perceptions of how the county Mental Health Court can increase engagement in outpatient services so that defendants will spend more time in the community and less time incarcerated?"Question number three asked, "What could we change in the system to increase service engagement?" However, there was not a clear consensus that current practice to engage people in outpatient services was either effective or ineffective. This ambivalence was further reinforced by comments associated with the current system of care. This raised the question of whether question numbers one and three of the focus group plan should be modified. The questions for the individual interviews did not appear to need modification. Question one for the focus groups asked about how engagement in outpatient services can be improved in order to reduce recidivism. This question assumed that the participants agree that engagement in outpatient services helps to reduce recidivism.

The purpose of using AI was to develop cohesion and transparency in the interest of improving outcomes through consensus on what "better" means [19]. In this case, "better" may mean reduced recidivism 
or it might mean improved outpatient service engagement. The group of research participants helped to improve on what we mean by "better" through the process of focus group meetings (Appendix A). To that end, it was necessary to modify question number one of the focus group to, "What are your perceptions of how the county MHC can support the community so that defendants will spend more time in the community and less time incarcerated?" Question number three was changed to, "How does our community currently work to reduce recidivism?" Focus groups were completed based on the modified starter questions.

\section{Interviews}

Malterud [20] describes a strategy for qualitative analysis called systematic text condensation. Based on the work of Amedeo Giorgi [21], Malterud suggests a more descriptive four-step analysis of qualitative data. This process begins with a total impression to establish an overview of the entire collection of data (metaphorically a "birds-eye view"). Here, the researcher identifies basic themes. Next, Malterud [20] suggests analyzing the data for elements that may illuminate the research question. This involves separating specific words from their context, in order to cross-reference terms within the theme "categories". Maltrud recommends flexibility in the third step, with abstracting meaning units, so that meaning is derived from the data and not the other way around. In the final step of this process, Malterud [20] describes the process of synthesizing the data into a narrative that reflects the phenomenon described by the data.

\section{Themes}

The purpose of the survey was to find out more about the respondents' perceptions about system strengths and needs in mental health service delivery for adults with serious mental illness who are involved in the legal system. The survey questions were written to include several primary words: help, service, and improving. The word "help" was associated with services helping offenders with serious mental illness and with collaboration being helpful to stakeholders' job success and to offender outcomes. "Service" was associated with mental health treatment services in terms of engaging offenders with serious mental illness and with the effectiveness of those services to improve outcomes for offenders. "Improving" spoke to the collaborative efforts of the two systems and to the effectiveness of mental health interventions to improve outcomes. Survey data reinforced the plan for individual interview starter questions and helped to improve on starter questions for the first focus group meeting. It was gathered early in the data-gathering phase so that it could help focus the individual interviews and the focus groups.

The results of the data were organized into categories based on topics that were determined from primary words that were based on the research plan. As the data was categorized, topics were created based on a meaningful system of labels. Categories were then clarified based on meaningful topics that are both internally homogeneous and externally heterogeneous. Each category was then assigned a number and then the narratives and transcripts were assigned a code, based on sub-topics within a category. For data compilation, the content of the individual interviews was considered, with particular attention on mental health service provider perspectives on interventions. Once the interviews were completed, the first two focus groups were completed and minutes were kept in the form of a field journal for documentation. In the final action, the final focus group solicited stakeholders for ideas about action steps that might be carried out.
The qualitative data were collected through individual interviews and focus group meetings that involved community service providers and local law enforcement. The face-to-face semi-structured interviews, with open-ended questions, were administered to each community mental health provider. The interviews were audio taped and transcribed. Microsoft Word was used to transcribe the data from the audio interviews verbatim. Field notes kept a record of the raw data to include field notes, interview transcripts, and focus group transcripts. The last analysis considered how these notes tie the process together.

Management and processing of the data included a thematic analysis to identify common themes that appear across the data. After the thematic analysis, systematic text condensation consisted of the following steps: listing themes, sorting meaning units (from themes to codes), and condensation of code to meaning [20]. Next, synthesizing the data took these concepts from condensation to descriptions and concepts. Data preparation and analysis consisted of compiling the categorized data into charts and reviewing for thematic patterns. The data was stored in a secure file drawer within the chambers of the MHC judge. Data will be securely stored in a locked space for seven years.

The individual interviews followed a plan of open-ended questions that help to answer the study sub-questions (Appendix A). The primary picture that was evident from the individual interviews was that direct services do not involve enough overall time (not just frequent contact, but more time spent). For example, Participant number seven stated, "They [Clients] need more frequent contact in person. They know they're falling through the cracks." The data also indicated that the direct care staff that provides most of the individual care is not skilled or are not properly directed on how to carry out an effective intervention. This idea was supported by reports of participants that suggests that staff-to-client-ratios are too high to facilitate effective care and that this may be caused or exacerbated by excessive bureaucracy that prevents funding from reaching the clientlevel intervention. For example, Participant number one stated that, “. . case management or even if its peer support, we get a steady flow of people that come in and we are not always able to take care of them; even if we want to."

Primary themes and issues that complicated collaboration between the justice and mental health service systems were identified by coding phrases that contain specific words into categories. It was important to categorize these ideas into themes by whether or not they were occurring at present and by whether or not they were helpful in achieving the goal of reducing recidivism for offenders with serious mental illness. This was done so that a plan for improvement would germinate.

The thematic analysis of the qualitative data determined three broad themes from the individual interviews. These themes include "things that are happening within mental health services and help to reduce recidivism," "things that help recidivism but are not happening," and "things that are not helpful but are happening" (see Table 2). These themes resulted from reading through the transcribed interviews and analyzing for overall perceptions. Table 2 illustrates how the transcripts and subsequent word search tied direct quotes from participants to a specific theme. This analysis provided substance to answering the overall research question by indicating that the mental health service providers believe that increasing service engagement 


\begin{tabular}{|c|c|c|}
\hline Things that are happening and help. & Things that help but are not happening. & Things that are not helpful but happening. \\
\hline $\begin{array}{l}\text { P4: "Helping people become more } \\
\text { independent is my job." }\end{array}$ & $\begin{array}{l}\text { P1: “... we get a steady flow of people that come } \\
\text { in and we are not always able to take care of } \\
\text { them, even if we want to." }\end{array}$ & $\begin{array}{l}\text { P1: “... when you are incarcerated ... you have } \\
\text { the ability to learn more of the criminal side of } \\
\text { things. }\end{array}$ \\
\hline $\begin{array}{l}\text { P10: "we now have an agency that will do } \\
\text { the ' } 24 / 7 \text { ' which is wonderful that we can } \\
\text { wrap around the 'Telecare." }\end{array}$ & $\begin{array}{l}\text { P4: “... [Staff] don't spend enough time with } \\
\text { [Clients]. They say, "hi" and leave." }\end{array}$ & $\begin{array}{l}\text { P1"... things happen all the time and we are } \\
\text { getting calls on the weekend ... let the members } \\
\text { know what other options are out there, so that } \\
\text { when things do come up they have someone to } \\
\text { call." }\end{array}$ \\
\hline $\begin{array}{l}\text { P10: "I think that [face-to-face contact] gives } \\
\text { us more of a rapport with the client. More } \\
\text { of a trust. Because that's a big deal to a lot of } \\
\text { people; the trust issue. The familiarity. The } \\
\text { safety." }\end{array}$ & $\begin{array}{l}\text { P7: “... Clients need more frequent contact in } \\
\text { person. They know they're falling through the } \\
\text { cracks." }\end{array}$ & $\begin{array}{l}\text { P7:"... Clients need contact immediately upon } \\
\text { signs of regression. There is no structured } \\
\text { environment available that is staffed } 24 / 7 . "\end{array}$ \\
\hline \multirow{3}{*}{$\begin{array}{l}\text { P12: "Service engagement is very important } \\
\ldots \text { especially between the jail and the } \\
\text { community transition." }\end{array}$} & $\begin{array}{l}\text { P7: "Clients need daily checks and ADL skill } \\
\text { training." }\end{array}$ & $\begin{array}{l}\text { P12: "There is lack of knowledge and education of } \\
\text { mental health." }\end{array}$ \\
\hline & $\begin{array}{l}\text { P12: “... Incarceration is stressful for the } \\
\text { person and the family. We need to teach self- } \\
\text { advocacy." }\end{array}$ & P13: "We have too many low skill providers." \\
\hline & $\begin{array}{l}\text { P13: "Communication between agencies falls } \\
\text { apart with staff that are not trained and high } \\
\text { turn-over." }\end{array}$ & $\begin{array}{l}\text { P13: "Processes are extensive to get a client into } \\
\text { services ... it is too bureaucratic, especially for } \\
\text { people with high needs." }\end{array}$ \\
\hline
\end{tabular}

Table 2: Themes from Individual Interviews.

helps defendants to spend more time in the community and less time in jail. This process also added validity to the study in terms of crossreferencing terms within each identified theme.

\section{Focus Groups}

Three focus group meetings were conducted formally, in meeting rooms within the county courthouse. Participants in the study were invited, with various individuals attending all or some of the focus group meetings.

The first focus group resulted in the identification of a need for more robust and timely release plans for offenders with serious mental illness (Appendix A). Notes from the whiteboard stated that release planning needs to begin "sooner in the process," needs to be automatic, and the information needs to be shared between the justice systems (i.e. Probation) and the mental health providers. The group noted that the need was great for this population, especially people who are not participants in the MHC. The group also identified a need for greater collaboration between the justice system, the mental health service system, and other systems such as law enforcement, psychiatric hospitals, and medical services at all levels. Notes from the whiteboard demonstrated that there was a need to educate the public (especially family members) and stakeholders about the crisis services that are available, and how to access them. The result was a recommendation for an ad-hoc community meeting that focuses on prevention (helping adults with serious mental illness to remain stable enough to avoid the need for higher-level services).

Based on the themes that evolved in the first focus group meeting (see Appendix A) the second focus group questions were modified to steer the discussion in the direction of specific intervention ideas. The second focus group was started with the following questions: How can we, as stakeholders, improve the current collaborative process of creating and implementing release plans from jail to the community? What can be done to improve the procedure for families and supportive others, who want to help a person get help in a mental health crisis and prevent arrest? The following seem to be helpful to reduce recidivism: How can we make the process and procedure more efficient and effective? How might we all benefit, to better understand the perspective of our collaborative peers in other systems? (Law enforcement, jail, service provider, justice system). What might a client identify as a goal of treatment, if she or he considered each system she or he is involved in (Law enforcement, jail, service provider, justice system)?

The group determined that key stakeholders were not a part of this research and an action plan was determined to reach out to these key people. The discussion included support for families during a mental health crisis that may result in an arrest for domestic violence, psychiatric treatment for offenders in the jail that are in need of psychiatric hospitalization, and support for law enforcement that contact a person with psychiatric symptoms that do not meet criteria for hospitalization. Each of these examples may result in an arrest that would be avoided if substantial treatment were offered. The stakeholder participant that was also a city police lieutenant stated, "There are other times when we stick around and we may get the result that they're not "Title 36able" [do not meet criteria for an involuntary emergency evaluation] and then we may opt to go the other direction to jail. I don't know how often families recognize and know that Nurse wise [the community crisis mental health line] exists." The result was a plan to focus our next meeting on an action plan that will address immediate psychiatric needs for people who are at risk of arrest while experiencing psychiatric symptoms.

The third focus group meeting held the purpose of developing action plan steps. The issues discussed in the previous meetings were summarized and reviewed (Figure 1). Improved outcomes and action steps that would result in these desired outcomes were considered. After discussing possible ways to educate the general public about the mental health crisis system, it was determined that this group was more capable of success with linking crisis services and the 


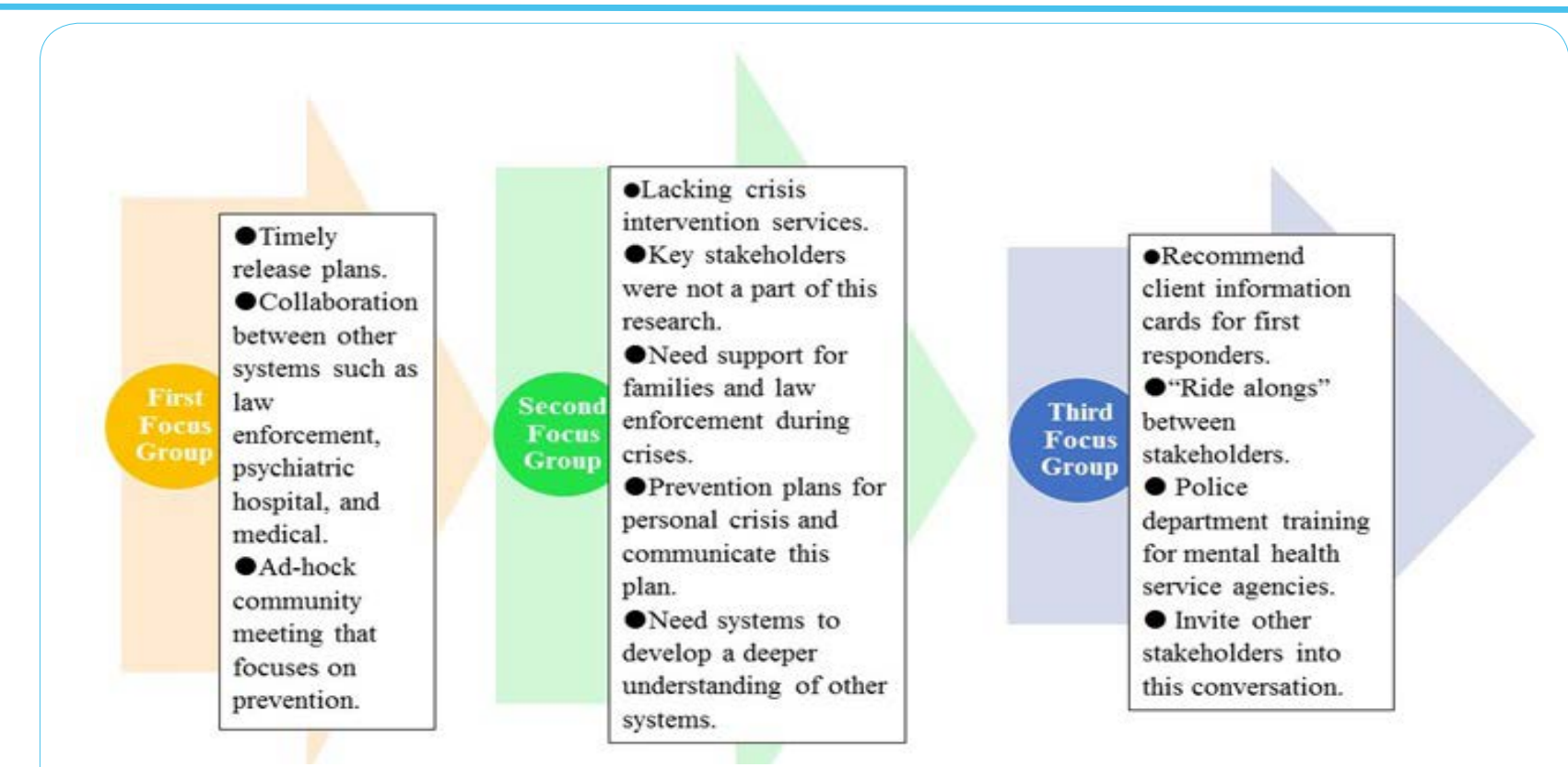

Figure 1: Themes from Focus Groups.

information they possess about an individual, with law enforcement during high risk police contact. The crisis intervention agency, the local police departments, the local hospital and fire and rescue were contacted. This was for pursuing information cards that clients could carry and present to first responders, so that a crisis may be averted or lessened. A plan was arranged for "ride along" between the local police department, for the local police department to provide training to each mental health service agency, to invite other stakeholders into this conversation.

The purpose of this AI was to explore the complex issues associated with helping adult offenders with serious mental illness to spend more time in the community and less time incarcerated. This study focused on improving the collaboration between the justice and mental health service delivery systems in order to increase service engagement. The study began with a brief Likert scale survey for the purpose of validating the direction of the qualitative data collection measures. Ultimately, the study was designed to explore and improve collaboration by first considering the perceptions of the mental health service providers associated with collaboration with the justice system.

The primary theory that guided this study was the ecological systems model, which illustrates that temperament, personality, intelligence and behavioral traits drive a person with serious mental illness's interaction with their environment [22]. The quality of social institutions such as schools, hospitals, and churches at the meso level further influenced community resources and extended family. The meso level of the offender with mental illness is impacted in a positive or negative way by political, geographical, environmental, or societal events in the macro level. Exploring service providers' perceptions of collaboration between systems based on the defendant's strengths and needs helped to focus improvement efforts that will eventually have a ripple effect and help the person to improve their quality of life by avoiding incarceration.

\section{Results and Discussion}

The key purpose of this study was to reduce recidivism through a process of collaboration between the MHC and mental health service providers as they work together to design new strategies to reduce recidivism among adult offenders with serious mental illness. This study followed a pragmatic approach that allowed for evolving assumptions about the causes that influence the outcomes. Through brainstorming and sharing "big ideas," this study applies AI to help facilitate improved processes that will help offenders with serious mental illness to avoid frequent incarceration. Legal professionals, mental health service providers, and professionals from the Adult Probation department were utilized as stakeholders. Individual interviews, focus groups, and a survey in an AI were utilized to explore effective ways to help offenders with serious mental illness to coexist successfully in the community and avoid further incarceration.

This research originated during a period of advocacy on behalf of adults with serious mental illness who found themselves chronically incarcerated as part of ongoing psychosocial problems associated with living in this community. I am a Licensed Clinical Social Worker (LCSW) who has worked in the field of social work for the past twentyseven years. I have worked in various organizations including those addressing psychiatric disorders, child, adolescent and adult mental health, substance abuse, and within the criminal justice system. My professional background and familiarity with the community was useful in establishing a rapport with the participants.

The National Association of Social Workers (NASW) Code of Ethics Section 3.07 states that social work leaders need to advocate for resources to help the needy, must advocate for fair resource allocation and to encourage subordinates to comply with the NASW Code of Ethics [23]. Social workers exist to enhance human well-being by helping to meet basic human needs, especially of the oppressed, the vulnerable, and those living in poverty [23]. This study fulfilled this responsibility by advocating for accessible and adequate mental health services for adult criminal offenders with serious mental illness.

\section{Summary of the Results}

Through the use of the survey, focus was improved for the individual interviews and focus group meetings. The survey helped to define perceptions about strengths and limitations associated with 
collaboration between the mental health service delivery and the legal system (Appendix A). The individual interviews helped to develop three broad themes around recidivism and the mental health system, and the focus groups helped move the analysis through an action research approach to action planning. There was general agreement in previous research $[3,4,6$,$] that offenders with serious mental$ illness find it more difficult to navigate the criminal justice system and that coordination between the outpatient mental health services and the judicial systems help to reduce recidivism rates among this population. However, there was not a clear consensus that current practice to engage people in outpatient services was either effective or ineffective. In relation to current practice associated with engaging people in outpatient services, this study suggests, from the individual interviews, that direct services do not involve enough overall time (not just frequent contact, but more time spent). The data also indicated that many staff that provided direct services are not skilled or are not properly directed on how to carry out an effective intervention.

The study provided substance to the research question that mental health service providers believe that increasing service engagement helps defendants to spend more time in the community and less time in jail, and that there are known factors that either help or do not help to achieve this desired outcome. Kopelovich, Yanos, Pratt, and Koerner [24], concluded that an increase in perceived procedural justice correlates with a decrease in symptom severity [24]. Therefore, adding depth and substance to collaboration by mental health providers with justice system professionals is likely to increase service engagement and perceived procedural justice. This demonstrates a link between mental health courts and psychotic symptom reduction in defendants with serious mental illness.

It is worthy to note that the first focus group meeting resulted in the identification of a need for more robust and timely release plans from jail for offenders with serious mental illness. The group also identified a need for greater collaboration between the justice system, the mental health service system, and other systems such as law enforcement, psychiatric hospital, and medical services at all levels. The result was a recommendation for an ad-hoc community meeting that focuses on prevention (helping adults with serious mental illness to remain stable enough to avoid the need for higher-level services). This conclusion is further supported by the research of Adams and Ferrandino [25], who concluded that inconsistent treatment between correctional facilities and outpatient services leads to lingering or escalating behavior, which in turn results in repeated incarceration.

The second focus group meeting identified a strong theme related to the need for improved crisis intervention services. This conclusion is in line with the research by Cloyes, et al. [12] that noted that inadequate outpatient mental health services often lead to medication non-adherence, which is also a factor in increased recidivism. This meeting group also determined that key stakeholders, which included professionals that work with community crisis intervention and psychiatric hospitalization, were not a part of this research and an action plan was determined to reach out to these key people. The discussion also addressed the need to better support family members during a mental health crisis, and the need to support and assist law enforcement that contact a person with psychiatric symptoms that do not meet criteria for hospitalization. Each of these examples may result in an arrest that would be avoided if substantial treatment were accessible. After discussing possible ways to educate the public about the mental health crisis system, the third focus group determined that it was more feasible for this group to look at ways to link crisis services with outpatient needs, possibly accomplished by sharing information.

These findings are also supported by research that suggests that it is more difficult for offenders with serious mental illness to navigate and successfully overcome involvement in the criminal justice system when compared to offenders who do not suffer from serious mental illness [3]. Additionally, inadequate outpatient mental health services that often lead to medication non-adherence between incarcerations was found to be a factor in favor of recidivism [12]Cloyes et al., 2010). Gideon [3] found that prison-based drug treatment reduces recidivism and that other factors, such as continued treatment after release and community-based support, were equally important. Kopelovich, Yanos, Pratt, and Koerner [24], concluded that an increase in perceived procedural justice correlates with a decrease in symptom severity [24]. This demonstrates a link between mental health courts and psychotic symptom reduction in defendants with serious mental illness. Therefore, Kopelvich, et al research suggests the MHC is now widely recognized as an effective way of disposing of these offenders. Improved mental health services collaboration with the legal and criminal justice system, promoted by policy and practice in and out of corrections may lead to lower costs to society by way of recidivism after release.

The overarching question for this AI study was, "What are mental health service providers' perceptions of how the county MHC can increase engagement in outpatient services so that defendants will spend more time in the community and less time incarcerated?" The question was answered in the individual interviews and the focus group meetings. The study demonstrated that the coordination of services that the MHC provides through holding stakeholders accountable for quality and timely services was essential to increasing service engagement and ultimately reducing recidivism. Prior to the advocacy of the MHC team, the process of planning for subsistence and mental health services upon release from incarceration was viewed as impossible because it was a non-billable service. Now, release planning is required and monitored by the administrative entity that oversees the use of Medicaid mental health service dollars (the Regional Behavioral Health Authority or RBHA).

Additionally, based on the needs of the defendant, provider agencies were held accountable by the Mental Health Court, to provide a continuous quality service. The content of the focus groups also included recommendations that the advocacy that stems from the MHC continue to demand intersystem collaboration and quality services that meet the individual needs of the defendant and his or her family. The steps of the AR process to uncover solutions through progressive problem solving activities allowed the study to suggest changes in the first focus group questions and one focus group meeting fed the agenda of the next. The greatest example of the effectiveness of this advocacy was that the service agencies added positions and requirements associated with treating adult offenders with serious mental illness.

\section{What are the mental health service stakeholders' perceptions of how to increase engagement in services?}

The individual interviews and focus groups gleaned qualitative data that described some bureaucratic barriers and some service adherence issues by the individual defendants. The bureaucratic barriers included things like hiring unqualified service providers, excessive workloads 
and caseloads, and staff turnover. Since the research began, mental health assessors are now required to hold a Master's degree and caseloads are held to a maximum of 20 for offenders with serious mental illness. Individual service adherence includes examples like not taking medications as prescribed and not attending group or individual service appointments. This was addressed through support of the MHC by mandating adherence to the individual service plan that was devised by the team, which includes the defendant, the service agency professionals, the probation officer, and other involved parties.

\section{What do the mental health service stakeholders identify as effective ways to address the current rate of recidivism?}

Based on the data collected from the individual interviews and the focus groups, service provider stakeholders of the MHC identified that incarceration seems to exacerbate symptoms of serious mental illness and the participants agreed that reducing recidivism was an important safety goal for the community. The data also indicated that improving crisis intervention services was an important objective toward meeting this overall goal. The group determined action steps associated with collaborating with community stakeholders to improve prevention and crisis intervention services. These action steps include creating an ad-hock community meeting for addressing emerging challenges related to break down in collaboration or communication between professional in all stakeholder systems. Another action step that was determined is to involve psychiatric hospital and crisis intervention professionals and administrators in the conversation about how and why to improve intersystem collaboration.

What are the mental health service stakeholder's ideas about service engagement time and quality?

The majority of the comments found in the data from the individual interviews could be categorized as recommendations to improve service engagement time and quality. Examples include participant number seven stating, "They [Clients] need more frequent contact in person. They know they're falling through the cracks." The data also indicated that the direct care staff that provide most of the individual care are not skilled or are not properly directedon how to carry out an effective intervention. For example, participant number one stated that, “. . . case management or even if its peer support, we get a steady flow of people that come in and we are not always able to take care of them; even if we want to."

What are the mental health service stakeholder's perceptions of their roles and responsibilities in the increasing the Defendants' level of commitment to service engagement?

During the individual interviews, the data suggests that provider stakeholders perceive that they are responsible to encourage and support service engagement that prevents recidivism. They seem to believe that they are doing what they can, given boundaries that are defined by agency administrators. While preparing for data collection, providers were given a new authorization to help defendants of the MHC plan for release from jail. This changed the role of case managers of mental health services and shifted their responsibility to help offenders with serious mental illness after release from jail.

\section{Limitations}

The most pronounced limitation that affected data collection was that there was a delay of two years between setting up the site and collecting research data. This influenced the motivation of potential participants and resulted in frustration associated with stakeholders believing that the research was going to provide recommendations in a timely manner. It also resulted in program changes that affected the research plan during the plan approval process.

Another limitation of the study was that it showed that stakeholders who did not participate in the research could only address some of the barriers to helpful collaboration between the judicial and mental health systems. This might have been avoided if the study was not grounded in the MHC. In other words, the study would have likely been more effective in determining actions steps if it included the broader community. One result of the study was an action plan to contact the other identified stakeholders and cultivate collaboration outside of this study.

With AI, the researcher determines the qualitative data collection modality and starter questions, which attempt to answer a predetermined research question. Gallagher and Heyne (2012) note that appreciative inquiry is sometimes criticized for being a slow process when needs are timely. Gallagher and Heyne also note that opponents of AI express concern that positive changes are short term and leaders must buy in to the change plan. This study attempted to alleviate these concerns by adding a quantitative survey to validate the direction, and thus save time, of the qualitative data collection methods and starter questions. This study also included openended questions that allow participants to answer according to their inherent thoughts so that thorough buy-in will solidify commitment. The study used three focus group meetings, which allowed for open conversation between group members so that those in leadership positions will feel heard.

\section{Conclusions}

The intent of the study was to increase collaboration between the two systems so that expectations placed on the defendant are consistent between the judicial and mental health treatment plans. The study validated the assumption that collaboration between the systems results in a united approach to reducing community crime and improving the quality of life for offenders with serious mental illness. Results of this project include action steps for this community to increase knowledge of other system goals, roles, and responsibilities and to combine individual case and system-to-system collaboration in the interest of duplicable and sustainable collaboration that improves outcomes for individuals and communities.

Collaboration between the justice and mental health service systems was complicated by the fact that providers perceived that there were interventions and approaches that were known to be helpful in reducing recidivism for offenders with serious mental illness, but were not in use. This research helped to define which methods of collaboration are occurring at present whether or not they were helpful to achieving the goal of reducing recidivism for offenders with serious mental illness. There was disagreement between the direct service providers and agency administrators because most of the discussions around this topic were related to staff workload and skills. Stated differently, interventions that are known to be helpful may not occur because of workloads and factors that are known to be futile. This seems to have a simple solution in terms of knowing what to do, yet challenging because the system seems to have a well-funded executive team and a minimally funded clinical team. The implication 
for practice is that policy efforts focus on outcomes related to reducing recidivism rather than on communicating through correct channels. This allows professionals to individualize collaboration based on what collaborative peers are involved and on the needs of the offender with serious mental illness. Practitioners will become less focused on the process of collaboration and more focused on the needs of the offender. This is likely to lighten turf issues and relieve strain between systems.

Continued care between jail and outpatient services often fails due to differences in medication formulary, and a drastic change in the level of supervision [4]. In the end, it is much more expensive to incarcerate individuals than to provide outpatient services, especially when the costs of arrest and court costs are considered. The longterm recommendation for future practice was to improve interagency communication related to effective engagement in psychiatric services that are duplicable among communities. The quality of outpatient service adherence and formal community supervision are positive factors in reducing recidivism [3]. Outpatient treatment of serious mental illness included regular visits with the prescribing psychiatrist. With proper medication, the disease progresses much more slowly, and people are often able to function well in the community [6]. Kilian et al. [4] reported that when a doctor, did not properly supervise offenders with mental illness by outpatient services, or by the court system, the outpatient plan became futile. Therefore, the proper engagement of all involved professionals will improve practice by inviting legal and mental health professionals to collaborate and identify interventions that will help to prevent recidivism among offenders with mental illness. These two systems of care work together to help adults with serious mental illness to avoid or reduce chronic legal involvement [26]. The desired objective of improving practice was to increase outpatient mental health service engagement with the purpose of reducing psychosocial problems that led to arrest and inpatient stays. Efforts to improve the effectiveness of outpatient services needs to concentrate on known resilience factors such as housing, supportive others, avoiding substance abuse, and adherence to psychological treatment recommendations. A supplemental recommendation was to develop written material in the form of training and TIPS that improve collaboration between the two systems that focuses on coordination of services that are continuous and ultimately reduce recidivism.

Statutes restrict courts regarding mandating compliance. However, the mental health service providers and others advocating for this vulnerable population have differing perspectives than the court. The court has the ability to mandate compliance, which was a beneficial tool to all of the providers. It is sometimes beneficial to have the court mandate follow-through so that offenders with serious mental illness will complete enough treatment to realize the benefits and then adhere voluntarily. With the court's use of mandating coercive measures as an acceptable and essential tool, the range of possible project goals includes the prevention of prison, treatment, and the recovery of emotional and mental distress.

Specifically, the recommendation was to stimulate a collaborative partnership of stakeholders wishing to improve collaboration between systems that prevents recidivism. The continuation of care was proven difficult due to differences in perspectives between mental health professionals and legal professionals. This is a nation-wide problem and not only will a positive impact improve the quality of life for these individuals, but the cost savings to taxpayers will be considerable because it is much more expensive to incarcerate individuals than to provide outpatient services [3]. Ultimately, a vulnerable population will be better served in the community rather than in a correctional facility.

Sustained care between correctional institutions and outpatient mental health services often fail due to differences in formulary and a drastic change in the level of supervision [4]. It is more expensive to incarcerate individuals than to provide outpatient mental health services. Before the nationwide MHC trend began, there was no proper standard for legal disposition of mentally ill criminals [28]. In some cases, the criminals were hospitalized and then discharged back to the community. This was not productive and offenders with serious mental illness continued to cycle through the legal system [29]. The MHC concept has allowed offenders to face sanctions or other appropriate consequences, partly based on a violation while participating in the MHC [30].

This study has created the opportunity to transform collaborative processes between the MHC and mental health service system. These two systems of care work together to help adults with serious mental illness to avoid or reduce chronic legal involvement [26]. The results of this study show a strong connection between avoiding recidivism and re-incarceration among adults with serious mental illness and collaboration that provides input from the mental health service providers, the court professionals, and the researcher. This will reduce the rate of recidivism by increasing service engagement and will stimulate an ongoing collaborative partnership of stakeholders wishing to improve outpatient services that prevent recidivism.

\section{Competing Interests}

The author declares that she has no competing interests.

\section{References}

1. Greenberg G, Rosenheck RA, Erickson SK, Desai RA, Stefanovics EA, et al. (2011) Criminal justice system involvement among people with schizophrenia.Community Mental Health J 47: 727-736.

2. Rossman SB, Willison JB, Mallik-Kane K, Kim K, Sherrill P (2012) Criminal Justice Interventions for Offenders with Mental Illness: Evaluation of Mental Health Courts in Bronx and Brooklyn, New York. National Institute of Justice.

3. Gideon L (2009) What shall I do now? Released offenders' expectations for supervision upon release. Int J Offender Ther Comp Criminol 53: 43-56.

4. Kilian R, Lauber C, Kalkan R, Dorn W, Rössler W, Wiersma D, Becker $T$ (2012) The relationships between employment, clinical status, and psychiatric hospitalization in patients with schizophrenia receiving either IPS or a conventional vocational rehabilitation programme. Soc Psychiatry Psychiatr Epidemiol 47: 1381-1389.

5. Stahl R, Shdaimah C (2008) Collaboration between community advocates and academic researchers: Scientific advocacy or political research. British Journal of Social Work 38: 1610-1629.

6. Kisely SR, Campbell LA, Preston (2011). Compulsory community and involuntary outpatient treatment for people with severe mental disorders. Cochrane Database Syst 16: CD004408.

7. Baillargeon J, Hoge SK, Penn JV (2010) Addressing the challenge of community reentry among released inmates with schizophrenia. Am J Community Psychol 46: 361-375.

8. Dirks-Linhorst A, Linhorst D (2010) Recidivism outcomes for suburban mental health court defendants. American Journal of Criminal Justice 37 : 76-91.

9. James D, Glaze L (2006) Mental Health Problems of Prison and Jail Inmates.Special Report, Bureau of Justice Statistics. 
Citation: Fulton L (2017) Improving Outcomes for Criminal Offenders with Serious Mental Illness. Int J Psychol Behav Anal 2: 132. doi: https://doi. org/10.15344/2017/2455-3867/132

Page 11 of 11

10. Tripodi S, Bledsoe S, Kim J, Bender K (2009) Effects of correctional-based programs for female inmates: Asystematic review. Research on Social Work Practice 21: 15-31.

11. Makarios M, Steiner B, Travis LF (2010) Examining the predictors of recidivism among men and women released from prison in Ohio.Criminal Justice and Behavior 37: 1377.

12. Cloyes K, Wong B, Latimer S, Abarca J (2010) Time to prison return for offenders with serious mental illness released from prison: A survival analysis. Criminal Justice and Behavior 37: 175-187.

13. Soderstrom IR (2007) Mental illness in offender populations: Prevalence, duty, and implications. Journal of Offender Rehabilitation 45: 1-17.

14. Walters ST, Neighbors $C$ (2011) College prevention: a view of present (and future) web-based approaches. Alcohol Res Health 34: 222-224.

15. Creswell J (2009) Research design: Qualitative, quantitative, and mixed methods approaches. Thousand Oaks, CA: SAGE Publications.

16. Redmond R, Curtis E (2009) Focus groups: principles and process. Nurse Res 16: 57-69.

17. AJ Onwuegbuzie, Leech NL, Collins KMT (2010) Innovative Data Collection Strategies in Qualitative Research. The Qualitative Report 15: 696-726.

18. Stringer E, Dwyer R (2005) Appreciative inquiry in human services. Alexandria, VA: Prentice Hall.

19. Reed J (2007) Editorial: Sexuality. International Journal of Older People Nursing 2: 62 .

20. Malterud K (2012) Systematic text condensation: A strategy for qualitative analysis. Scandanavian Journal of Public Health, 40,795.

21. Giorgi A (Ed.) (1985) Phenomenology and psychological research Pittsburgh, PA: Duquesne University Press.

22. Howe D (2009) A brief introduction to social work theory.New York, NY: Palgrave Macmillan.

23. London and Philadelphia: Jessica Kingsley Publishers. National Association of Social Workers Code of Ethics (2008).

24. Kopelovich S, Yanos P, Pratt C, Koerner J (2013) Procedural justice in meantal health courts: Judicial practices, participant perceptions, and outcomes related to mental health recovery. Int J Law Psychiatry 36: 113120

25. Adams K, Ferrandino J (2008) Managing mentally ill inmates in prisons Criminal Justice and Behavior 35: 913-927.

26. Wales H, Hiday V, Ray B (2010) Procedural justice and the mental health court judge's role in reducing recidivism. Int J Law Psychiatry 33: 265-271.

27. Arizona Health Care Cost Containment System (AHCCS) (2015) Governor Ducey's Administrative Simplification. First Regular Session-52nd Legislature.

28. McNiel D, Binder R (2010) Stakeholder views of a mental health court. Int J Law Psychiatry 33: 227-235.

29. Rotter M, Carr A (2011) Targeting criminal recidivism in mentally ill offenders Structured clinical approaches.Community Ment Health J 47: 723-726.

30. Castellano U, Anderson L (2012) Mental health courts in America: Promise and challenges. American Behavioral Scientist 57: 163-173. 


\section{Appendix A. Questions for Focus Groups, Interviews and Survey}

Plan for Focus Group, Interviews and Survey

Study Question: "What are mental health service providers' perceptions of how the county Mental Health Court can increase engagement in outpatient services so that defendants will spend more time in the community and less time incarcerated?"

The goal of the study is to reduce recidivism and jail days for offenders with schizophrenia. Short-term objectives that are steps to goal achievement include the following:

1. Identify the barriers to service engagement (frequency and quality of mental health services).

2. Define current practice associated with engaging offenders with schizophrenia in mental health services.

3. Identify risk factors for recidivism that can be mitigated with mental health services.

4. Define current roles and responsibilities of the mental health service providers who help offenders with schizophrenia.

In order to answer the overarching research question, we will need to answer the following sub-questions:

\begin{tabular}{|l|l|l|l|}
\hline Sub-Question & Data Source 1 & Data Source 2 & Data Source 3 \\
\hline $\begin{array}{l}\text { What are the mental health service provider stakeholders' } \\
\text { perceptions of how to increase engagement in services? }\end{array}$ & Survey & Individual Interviews & Focus Group \\
\hline $\begin{array}{l}\text { What do the mental health service provider stakeholders identify as } \\
\text { effective ways to address the current rate of recidivism? }\end{array}$ & Individual Interviews & Focus Group & $\begin{array}{l}\text { Field Notes (anecdotal } \\
\text { observations derived from staffing } \\
\text { cases) }\end{array}$ \\
\hline $\begin{array}{l}\text { What are the mental health service provider stakeholder's ideas } \\
\text { about service engagement time and quality? }\end{array}$ & Survey & Individual Interviews & Focus Group \\
\hline $\begin{array}{l}\text { What are the mental health service provider stakeholder's } \\
\text { perceptions of their roles and responsibilities in the increasing the } \\
\text { Defendants' level of commitment to service engagement? }\end{array}$ & Individual Interviews & Survey & Field Notes \\
\hline
\end{tabular}

Individual Interview Starter Questions:

1. What do you see as risk factors for recidivism for people with schizophrenia?

2. How important is the frequency and quality of service engagement for people with schizophrenia who are also involved in the legal system?

3. Do you have any concerns about service engagement time and quality?

4. What are some of the barriers to addressing recidivism for people with schizophrenia who are also involved in the legal system?

5. How do you feel about your roles and responsibilities in increasing the offender's level of commitment to service engagement?

\section{Focus Group Questions:}

1. What are your perceptions of how the county Mental Health Court can increase engagement in outpatient services so that Defendants will spend more time in the community and less time incarcerated?

2. What do you identify as barriers to addressing the current rate of recidivism?

3. What could we change in the system to increase service engagement?

4. What are challenges to frequent and high quality service provision?

5. What are your perceptions of your roles and responsibilities in the increasing the offenders' level of commitment to service engagement?

Survey Questions:

\section{Likert scale questionnaire}

This is a survey to find out more about your perceptions about system strengths and needs in mental health service delivery for adults with schizophrenia who are involved in the legal system. Read each sentence and indicate your level of agreement.

\begin{tabular}{|c|c|c|c|c|c|}
\hline & $\begin{array}{l}\text { Strongly } \\
\text { Disagree }\end{array}$ & Agree & Neither & Disagree & $\begin{array}{l}\text { Strongly } \\
\text { Disagree }\end{array}$ \\
\hline \multicolumn{6}{|l|}{ Question } \\
\hline \multicolumn{6}{|l|}{$\begin{array}{l}\text { Engagement in outpatient mental health services helps people with schizophrenia to avoid legal } \\
\text { problems. }\end{array}$} \\
\hline \multicolumn{6}{|l|}{$\begin{array}{l}\text { Current practice associated with engaging offenders with schizophrenia in mental health services } \\
\text { is adequate in thecounty. }\end{array}$} \\
\hline \multicolumn{6}{|l|}{$\begin{array}{l}\text { Community stakeholders (service providers, the courts, probation, law enforcement) agree on } \\
\text { risk factors for recidivism that can be mitigated with mental health services. }\end{array}$} \\
\hline \multicolumn{6}{|l|}{$\begin{array}{l}\text { I fully understand my roles and responsibilities as a mental health service provider who helps } \\
\text { offenders with schizophrenia. }\end{array}$} \\
\hline \multicolumn{6}{|l|}{ There is a friendly feeling between service providers and other stakeholders. } \\
\hline There is a lot of wasted time in meetings about specific cases with similar barriers to treatment. & & & & & \\
\hline
\end{tabular}

